\title{
Reliability of bathymetric data in Italian nautical charts and ENCs.
}

\author{
Manuela Milli $^{\mathrm{a}}$, Cristina Tirone ${ }^{\mathrm{a}}$ \\ ${ }^{a}$ Italian Hydrographic Institute, Passo all'Osservatorio 4, 16136 Genova, Italy. \\ e-mail:*manuela_milli@marina.difesa.it,cristina_tirone@marina.difesa.it \\ * Corresponding author
}

Keywords: Quality of bathymetric data, Survey reliability, Zone of Confidence, Temporal variation.

\begin{abstract}
:
Over the past 20 years, nautical cartographic production has undergone a rapid evolution, moving from analogical to digital processes and decisively heading for the e-navigation concept, whose one of the core objective is to facilitate safe and secure navigation of vessels with regard to hydrographic data.
\end{abstract}

In accordance with the amendments to the International Convention for the Safety of Life at Sea (SOLAS), the seafarers have switched from the traditional paper charts unfolded on the nautical desk, to the Electronic Navigational Charts (ENCs) displayed on the screen of an Electronic Chart Display and Information System (ECDIS).

In so doing, nautical charts definitely turned from a navigational tool to a valuable strategic and operational means in support of real-time decisions.

The Italian Hydrographic Institute (Istituto Idrografico della Marina-IIM) is the national cartographic authority charged of producing and updating all the official nautical documentation relating to national waters. The area of competence of the IIM amounts approximately to $560.000 \mathrm{~km}^{2}$. To this day, the $50 \%$ of the IIM area of competence turns out to be surveyed by modern survey echo-sounder; the 48\% through data acquisition systems dated 1920-1970 and the residual 2\% with old systems, in use before 1920 .

Starting with an overview of the standard for hydrographic surveys, this paper delves into the quality and reliability of depth information shown on official nautical paper charts or displayed in an ECDIS.

The Italian Hydrographic Institute in order to comply with the technical specifications published by the International Hydrographic Organization (IHO) has revised over the years the way of providing the seafarers with the details of each individual survey used to compile charts, whether paper or ENCs. Bathymetric data quality varies due to the age and accuracy of hydrographic surveys and therefore needs to be properly quantified and conveyed to the users, in order to enable them to straightforwardly assess the level of reliability of information, in this way distinguishing which areas should be navigated with more caution than others.

The paper is concerned with the enhancement of the Source Diagram inserted on official Italian nautical charts over the years and its relation with the meta objects Quality of data (M_QUAL) and Survey reliability (M_SREL) encoded in the corresponding ENCs. It explains how the IIM allocates the Category of zone of confidence in data (CATZOC) value to the Italian ENCs' portfolio and describes how the seafarers have been made awareness of the degree of confidence they should have in the adequacy and accuracy of charted depths.

In addition this contribution delineates the metadata features expected with regard to the quality of bathymetric data for the new generation of ENCs based on the IHO's framework S-100 Universal Hydrographic Data Model. A suitable assessment of the quality of bathymetric data will include not only the completeness of data and their uncertainty but also an analysis of the characteristics of the area concerned along with the changeability of the bathymetry, its possible variation and the currency of data with respect to time.

The category of temporal variation will modify the quality of bathymetric data concept of the next generation of ENCs. In the future the challenge will be to relieve the mariners of the task to individually downgrade the level of confidence allocated to the charted depths, due to the time elapsed between the date the hydrographic data were collected, processed und finally used. 
Therefore, new approved S-100 ECDIS will also be necessary: these should be able to automatically downgrade the quality of bathymetric data, so as to have a direct impact on display, route planning and route monitoring, in this way facilitating awareness and decision-making processes.

\section{References:}

- Dorst L., Howlett C. (2012). Safe Navigation with Uncertain Hydrographic Data - The Representation of Data Quality in the IHO S-101 Data Model. Tech.rep. Hydro International.

- Gladisch S., Ruth T. (2016). Data Quality Visualization. Recommendations for Visualizing Uncertainty in Electronic Nautical Charts. Fraunhofer-Institut für Graphische Datenverarbeitung. www.igd.fraunhofer.de

- IHO (2020). IHO Standards for Hydrographic Surveys. Publication S-44.Ed.6.0.0.

- IHO (2020). Mariners' Guide to Accuracy of Depth Information in Electronic Navigational Charts (ENC). Publication S-67. Ed. 1.0.0.

- IHO (2018). Regulations of the IHO for International (INT) charts and chart specifications of the IHO. Publication S-4. Ed. 4.8.0.

- IHO (2018). IHO Electronic Navigational Chart product specification. Publication S-101. Ed.1.0.0

- IHO (2014). IHO Transfer standard for digital hydrographic data. Supplementary Information for the Encoding of S57 Edition 3.1 ENC Data (S-57 Supplement N. 3).

- IHO (2000). IHO Transfer standard for digital hydrographic data. Publication S-57 Ed.3.1.

- IIM (2021). Disciplinare tecnico per la standardizzazione dei rilievi idrografici. Ed.2.

- Weintrit A. (2018). Accuracy of bathymetric data in electronic navigational charts. Scientific Journals of the Maritime University of Szczecin. DOI: 10.17402/302 